\title{
Effect of luting agent on the bond strength of ceramic-based li- thium disilicate and titanium abutment subjected to artificial aging
}

Washington Reis Leite¹, Paulo Henrique De Souza Pereira1', Laís Regiane Da Silva-Concílio', Ana Christina Claro Neves ${ }^{1}$ and Leonardo Gonçalves Cunha².

${ }^{1}$ Department of Prosthodontics, University of Taubate, Taubate, SP, Brazil. Expedicionário Ernesto Pereira St, 110. Centro, Taubaté, São Paulo, BRAZIL, ZIP code: 12020-330. ${ }^{2}$ Dental Clinic Department, University Federal of Bahia, Salvador, BA, Brazil. Araujo Pinho St, 62 Canela, Salvador, BA, Brazil, ZIP code: 40110-060.

\begin{abstract}
Objective: This study aimed to evaluate the bond strength (BS) of a ceramic coping-abutment implant interface according to the luting agent, before and after thermal cycling (TC). Methodology: Forty ceramic copings and abutments (Ti) were divided into four groups ( $n=10)$ : OZ (zinc oxide eugenol free), PZ (zinc phosphate), GIC (resin modified glass ionomer), and RC (adhesive resin cement). BS test was performed using a universal testing machine before and after TC. Analysis of variance (ANOVA) and Tukey test $(p<0.05)$ were performed for the means. Results: The results showed that before TC, the values ranged from $50.77 \mathrm{~N}(\mathrm{OZ})$ to $240.21 \mathrm{~N}(\mathrm{GIC})$. After TC, the values showed intermediate results $-3.5 \mathrm{~N}(\mathrm{OZ})$ and $330.66 \mathrm{~N}(\mathrm{RC}), 90.58 \mathrm{~N}(\mathrm{PZ})$, and $280.43 \mathrm{~N}(\mathrm{GIC})$. OZ performed the worst, both before and after TC. Before TC, GIC had the highest value. After TC, RC had the highest value of BS. Conclusions: The aging process influenced and inverted the results of the GIC and RC groups, and had a greater negative impact on the OZ group.
\end{abstract}

Keywords: Luting agent; Bond; Lithium disilicate; Artificial aging.

\section{Introduction}

The implant-prosthesis longevity is directly linked to the apparent success of osseointegration ${ }^{1-3}$. However, according to the same technological evolution, the behavior of implants used initially showed excellent results in cases where they were joined by a rigid mechanism. With increasing applicability of oral implants for tooth restorations, connections started to assume another role of preventing the rotation of the prosthesis. Furthermore, factors such as reversibility, esthetics, retention, passivity, and occlusion also emerged in the planning of these crowns, further contributing to an increase in their survival ${ }^{4,5}$.

The connections on the prosthetic implant may be made in accordance with the clinical positioning and biomechanical considerations in two ways: cemented prostheses and screwed prostheses. The cemented prosthesis is more esthetic and presents a better biomechanical behavior; this makes it ideal for use in implants conections However, despite representing the most commonly used type, this prosthesis poses a major challenge for dental surgeons. Different cements including zinc phosphate, type I glass ionomer, resin-modified glass ionomer, and resin cements, are commercially available for this purpose.

Temporary cement can be used for the bonding of the crown and the prosthetic implant pillar ${ }^{6,-8}$. This technique would make this stage reversible stage, thus solving the technical difficulty. The combination of petroleum jelly with temporary cement, can also be used to facilitate the removal of the prosthetic crown, if necessary ${ }^{6}$. However, the use of temporary cements could result in frequent recementation, in contrast to the high retention provided by zinc phosphate, glass ionomers, and resin cements ${ }^{9}$.

The high concern for esthetics has been evidenced in several areas of health, and dentistry is no exception. This has further advanced the search for new materials that are more esthetic. Among them is the ceramic synthesized from a lithium disilicate matrix and materials such as zirconia are recently used. However, new materials and methodologies for analyzing these materials have mainly been discussed in relation to the adhesion of these materials to metal coopings $^{10,11}$. This is important owing to the high demand for this treatment option in oral rehabilitation, especially in cases where esthetics play a major role.

Another aspect to be considered is the thickness of the film of cements between the prosthesis and the abutment. When performing a comparison between teeth and implants, it is observed that the natural teeth can move within one hundred micrometers of the periodontal ligament, compensating for the maladaptation of the prosthesis. In contrast, an osseointegrated implant has extremely limited motion, averaging ten micrometers ${ }^{10}$. The consequence of the absence of good adaptation, as in the case of thick-film cement, is the micromovements of prosthetic components. These micromovements may disrupt the pillar-cement interface. Addition different studies have shown that dental materials are susceptible to degradation when exposed to different periods and ways of storage ${ }^{11}$, influencing the bond strength of this interface ${ }^{12}$. The occurrence of such degradation is directly related to the composition of these materials, due to the loss of their constituents to the storage media. Moreover, the particles of the storage media can degrade the absorbed interface formed, resulting in decreased bond strength of this interface ${ }^{12}$. However, it is important to evaluate the behavior of this interface while bonding prosthetic pieces free of metal. Its adhesive properties may indicate different results, and even a different cementation technique $e^{9,26,32}$. According to the literature, dimethylmethacrylate-based cements show mechani- 
cal and chemical properties with superior adhesion $^{26,32}$ when compared to other cements. This study hypothesized that the dimethylmethacrylate-based cement shows superior bonding strength values when compared to other sealers, and that the influence of thermal cycling decreasing these values. Thus, the objective was to evaluate the bond strength and influence of thermocycling on the bond strength of the interface between different cementing agents and a ceramic system based on lithium disilicate and a metal pillar (Ti).

\section{Material and Methods}

Fifty dental implant analogs were used from the Regular Neck System (Straumann/ITI - Waldenburg, Switzerland) along with the assembler of the RegularNeck implant, forming fifty sets of implant/implant assembler. The dental implant analogs were fixed with the vertical rod of a cast surveyor (Bioart, São Carlos, SP, Brazil) in an epoxy resin-glass fiber composite, (NEMA Grade G-10 rod, Piedmont Plastics, Charlotte, NC, USA). This embedment material has an appropriate elastic modulus to serve as analog for bone (approximately $20 \mathrm{GPa}$ ); moreover, it can be machined easily and is sufficiently tough for cyclic testing20).

The sets of analog/implant assembler/linker were included perpendicularly in auto-polymerizable acrylic resin (JET - Artigos odontológicos, São Paulo, SP, Brazil), in PVC pipe (Tigre -São Paulo, SP, Brazil), totaling prosthesis laboratory authorized by the manufacturer.

\section{Torque procedure}

We used 50 solid pillars of $5.5^{\circ}$ to $8^{\circ}$ taper (Straumann No. 048541/ITI, Waldenburg, Switzerland). The analog/abutment assembly was torqued using a torque control device in a PVC pipe with a standardized torque force of $35 \mathrm{~N}$. All instruments and implant components were obtained from the same company (Straumann Dental System, Waldenburg, Switzerland) and the study protocol was in accordance with the manufacturers' instructions.

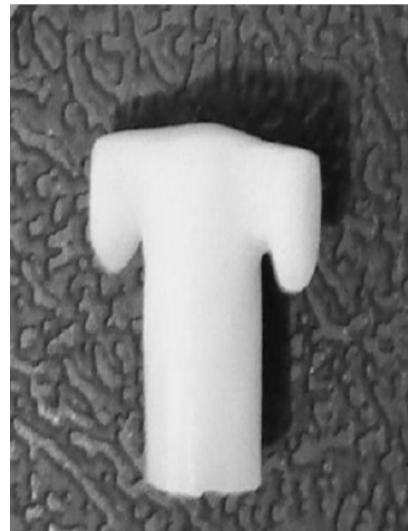

Figure 1 - Ceramic coping modified with two handles for testing tensile bond strength

\begin{tabular}{cccl} 
Table 1 - Material used in the study. & & \\
\hline Cementing Agent & Type & Classification & \multicolumn{1}{c}{ Manufacturer } \\
\hline Temp-Bond NE & Zinc Oxide & Temporary & SDS Kerr (CA - USA) \\
HY-Bond & Zinc Phosphate & Final & $\begin{array}{l}\text { Shofu Ind. ( San Marco CA } \\
\text { USA }\end{array}$ \\
GC Fuji Plus & Glass Ionomer & Final & $\begin{array}{l}\text { GC Corporation ( Alsip - IL } \\
\text { USA) }\end{array}$ \\
Modified by Resin & Fintlink & Final & $\begin{array}{l}\text { Ivoclar-Vigodent } \\
\text { (Multilink,Ivoclar-Vivadent, } \\
\text { Liechtenstein) }\end{array}$ \\
\hline \hline
\end{tabular}

50 samples. These were prepared in accordance with the manufacturer's specifications for lithium disilicate (IPS e.max, Ivoclar-Vivadent Nichestein - Germany); a total of 50 ceramic copings modified with 2 handles were used for testing tensile bond strength (Figure 1). After application and polishing of the copings, the dimensions of all were checked with Absolute ip 66 digital caliper (Mitutoyo, São Paulo, SP- Brazil). Any manufacturing defect such as cracks, porosity, or lack of proper dimensions led to exclusion of the sample.

The copings were stored in plastic containers in a dry environment without the interference of light and room temperature until completion of cementing. All bodies-of-evidence were fabricated in the

\section{Cementation (Phase 1)}

We randomly selected 40 copings (other ten were reserved) prepared in this study. These were randomly divided into four groups, with 10 elements each, for the cementation procedure (Table 1).

A device made to standardize the procedure for cementing was used for all study groups in this step. This device comprises of a piston coupled to a hole height adjuster, which enables control of the load applied for cementation; a total load of three pounds was used. The ceramic copings were then cleaned with an isopropyl alcohol swab for removing the impurities and/or contaminants from the ceramic surface. They 
were then cemented to the implant abutments embedded in acrylic resin, as described below (Table 2).

\section{Statistical Analysis}

The averages of the tensile bond strengths before and after thermal cycling were tested for normality (Kolmo-

\begin{tabular}{|c|c|}
\hline GROUPS & CEMENTATION \\
\hline Zinc Oxide $(\mathrm{OZ})$ & Cementation with zinc oxide according to the manufacturer \\
\hline Zinc phosphate (PZ) & Cementation with zinc phosphate according to the manufacturer \\
\hline Glass ionomer cement (GIC) & Cementation with GIC according to the manufacturer \\
\hline Resin cement (RC) & $\begin{array}{l}\text { The copings were etched with } 10 \% \text { hyaluronic acid for } 120 \mathrm{~s} \text {, } \\
\text { washed thoroughly with running water, placed in ultrasound for } 5 \\
\text { minutes and dried with air jets. Was applied a layer of silane } \\
\text { (Multilink (Ivoclar-Vivadent, Liechtenstein) specific for ceramic } \\
\text { was applied to the inner portion of cooping and silane layer to } \\
\text { metals on the internal surface of the pillar Multilink (Ivoclar- } \\
\text { Vivadent, Liechtenstein). The cementation was performed with } \\
\text { the self-curing resin cement.Set remained under the action of the } \\
\text { device for fifteen minutes, and, during this time, was performed } \\
\text { the removal of luting agent excess. Subsequently, the samples } \\
\text { were stored at } 37^{\circ} \mathrm{C} \text { for } 24 \text { hours. }\end{array}$ \\
\hline
\end{tabular}

\section{Bond strength (phase 1)}

After cementation, the samples were stored in $100 \%$ humidity at $37^{\circ} \mathrm{C}$ for 24 hours. The tensile bond strength test was performed in a universal testing machine (Versat 2000, Panambra, Sao Paulo, SP, Brazil), at a constant speed of 1.0 $\mathrm{mm} /$ minute until the displacement of ceramic coping of the implant solid pillar surface (Figure 2). After the displacement of the ceramic coping of the implant solid pillar surface, the values obtained in kgf were converted into Newtons.

\section{Cleaning copings and Cementantion (phase 2)}

Upon completion of the endurance test of the initial traction union, copings of the groups $\mathrm{OZ}, \mathrm{PZ}$, and GIC underwent cleaning to remove any residual cement and were subsequently cleaned with alcohol. The copings of the $\mathrm{RC}$ group were discarded because they had previously been subjected to surface treatment with hydrofluoric acid. The 30 cleaned copings, along with 10 new copings that were initially reserved, were randomly distributed between the groups.

\section{Thermocycling}

After completion of cementing, the samples were subjected to simulated aging by thermal cycling. For this, we used a thermal cycling machine (MCT2, AMM2, São Paulo, Brazil), composed of three different containers filled with water at three different temperatures: $50 \mathrm{C} \pm 1^{\circ} \mathrm{C}, 25^{\circ} \mathrm{C} \pm 1^{\circ} \mathrm{C}$, and $550 \mathrm{C} \pm 1^{\circ} \mathrm{C}$. The samples were subjected to temperatures of $5^{\circ} \mathrm{C} \pm 1^{\circ} \mathrm{C}$ and $55^{\circ} \mathrm{C} \pm 1^{\circ} \mathrm{C}$; an immersion in both constituted a cycle of immersion. Three thousand cycles were performed, and in each cycle, the samples were kept in each container for 60 seconds, with an interval of 7 seconds between each.

\section{Bond strength (phase 2)}

After the thermocycling, all samples of the different groups were tested for tensile bond strength, following the same parameters as previously described.
gorov-Sminov, Grip: Lilliefors). These were found to be normal, and subsequently, the scores were subjected to analysis of variance (two-way ANOVA) and Tukey's test for post hoc analysis, with a significance level of $5 \%$.

\section{Results}

The means values of tensile bond strength of different luting agents before and after thermal cycling are presented in Table 3.

Prior to the thermal cycling, the average values of bond strength for different cements ranged from $50.77 \mathrm{~N}$ (zinc oxide) to $240.21 \mathrm{~N}$ (glass ionomer). The zinc oxide cement did not differ statistically from the zinc phosphate cement (60.16 N). However, both showed average bond strengths statistically inferior to glass ionomer cements and re$\sin (230.36 \mathrm{~N})$, which did not differ from each other.

After completion of thermocycling, the average values of bond strength for different cementing agents were between $3.50 \mathrm{~N}$ (zinc oxide) to $330.66 \mathrm{~N}$ (resin). The resin cement had an average bond strength statistically superior to that of other groups in the study, followed by glass ionomer cement $(280.43 \mathrm{~N})$, and zinc phosphate cement $(90.58 \mathrm{~N})$, which were statistically different. The zinc oxide cement was associated with the lowest average tensile bond strength, which was significanty lower than the other study groups.

The completion of thermal cycling resulted in a statistically significant reduction in the average bond strength of zinc oxide cement without eugenol. For other cementing agents, thermocycling promoted a statistical increase in the average values of bond strength.

\section{Discussion}

Osseointegration has been promoted in the scientific literature as a dental specialty for over 40 years ${ }^{1,3,4}$. Its evolution over the years has allowed a huge technological revolution for both materials used in the manufacturing of dental implants and materials for fabrication of prosthetic crowns. Among these materials, dental ceramic-based lithium disilicate 
IPS e.max (Ivoclar-Vivadent, Nichestein - Germany) is being widely tested on implants for its favorable esthetic, mechanical, and especially physical and chemical characteristics ${ }^{25}$. These dental materials have already been studied and evaluated in the scientific literature, with a successful predictable outcome 1,2,22,25. $^{\text {. }}$ The fixation of prosthetic crowns on im-

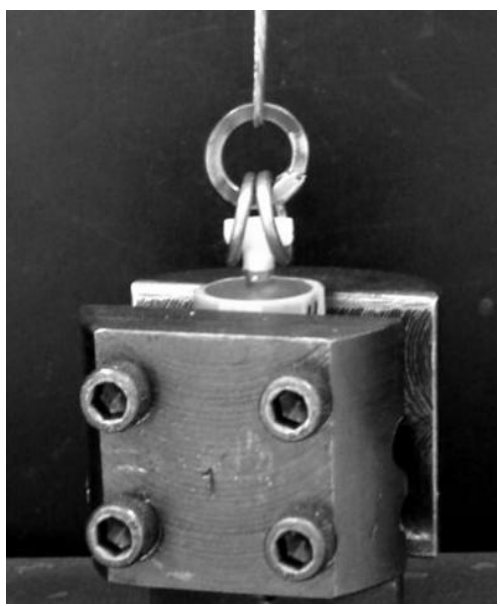

Figure 2 - Test for bond text of the various cements proposed by this study39.

The reversibility of the prosthesis was considered a major factor at the beginning of implantology because the dentist should be able to disassemble and reassemble screwed implants 24 , for maintenance and adjustments. Therefore, it was necessary to use temporary dental cements for cemented prostheses 13 , However, with the advent of prosthetic connections of cone-morse, this problem of prosthetic reversibility was remedied, as no longer required the removal of crowns after the final cementation because the connections have become more stable and reliable, with screwed prostheses being used only for short prosthetic crowns6). However, no consensus regarding the cementation protocols of ceramic copings, unlike that of lithium disilicate on implant abutments, exists in the literature. This cementing protocol still needs a longer evaluation period38). Although a conclusive protocol does not exist, studies have reported effective adhesion with metal-free cements34,35,36,37.

This study used four cements: Temp-Bond NE, GC Fuji Plus, HY-Bond, and Multilink. Their performances were compared in vitro in relation to the tensile bond strength between the substrate and the ceramic

Table 3 - Average values of tensile bond strength $(\mathrm{N})$ for dental cements evaluated before and after thermal cycling.

\begin{tabular}{cll}
\hline Groups & Pre-Cycling & Post-Cycling \\
\hline OZ & $50,77(1,53) \mathrm{A}, \mathrm{b}$ & $03,50(0,09) \mathrm{B}, \mathrm{d}$ \\
PZ & $60,16(1,82) \mathrm{B}, \mathrm{b}$ & $90,58(1,62) \mathrm{A}, \mathrm{c}$ \\
GIC & $240,21(2,19) \mathrm{B}, \mathrm{a}$ & $280,43(5,32) \mathrm{A}, \mathrm{b}$ \\
CR & $230,36(4,49) \mathrm{B}, \mathrm{a}$ & $330,66(6,40) \mathrm{A}, \mathrm{a}$ \\
\hline
\end{tabular}

*Averages followed by different uppercase in the rows and lowercase letters in columns differ statistically from each other $(p<0.05)$, according to the Tukey test.

plants can be performed in two ways: first by fixing the prosthetic crown using a screw on the implant or abutment, and second, by cementing the crown on this abutment. When the esthetic factor is determinative of this decision, cemented prosthesis should be selected. A good esthetic restorative material can result in a favorable outcome of the clinical case $e^{6,22,28}$. In this study, the focus was on these two aspects of rehabilitative treatment: the use of a lithium disilicate-based (coping), and cementing the abutment using different cementing agents. We thus evaluated the best interactions against resistance of the coping/abutment, as well as the effect of the aging method (thermal cycling) on the bond strength of the cementing agent. The cementation of an implant abutment with metallic copings has been widely discussed in the literature ${ }^{20,23,26,31}$, while the cementation with lithium disilicate on implant still needs a larger study, detailed and thorough in addressing the numerous difficulties relating to the surface treatment of these materials and its low adhesiveness with respect to cements. Creation of a rigid surface contact between the cement and the ceramics has become a topic of extensive discussion, especially in con- lithium disilicate implant abutment of ITI/Straumann before and after thermocycling. These cements were chosen using as references studies that used similar representatives of these cementing agent groups, applied to the tooth substrate 34,35 over other types of implants ${ }^{8}$ or on Straumann/ITI, Waldenburg, Switzerland, especially for the use of metallic coping ${ }^{20,23,31}$.

The average values of adhesiveness of resin cements used in this study are $0.76 \pm 0216$, which suggest a greater adhesiveness of resin cements. The cements tested were evaluated at two different times: before and after thermal cycling, by performing a test for tensile bond strength. According to the results obtained, Temp Bond cement $(3.50 \mathrm{~N})$ did not show values of bond strength sufficient for it to be adopted as temporary cement at the time post-cycling. The Hy-Bond cement $(90.58 \mathrm{~N})$ can be used as temporary cement due to the average bond strength obtained after thermal cycling. The Fuji Plus cement $(280.43 \mathrm{~N})$ can be used as a permanent cement because of the average bond strength obtained after thermal cycling, and the Multilink cement $(330.66 \mathrm{~N})$ obtained the greatest average tensile bond strength of all ce- 
ments tested in the present study after thermocycling owing to its high adhesiveness. This high adhesiveness of Multilink cement could be due to the conditioning of the surface of prosthetic pieces/metal copings with the adhesive-bonding agent (silane) -hyaluronic acidcooping bonding agent set system, this treatment was not performed for other cementing agents $5,8,15,20$.

With the exception of zinc oxide cement, the behavior of all other cements (RC, PZ, GIC) was positively affected by thermocycling, which increased the strength of bonding of the evaluated interfaces. A possible explanation for these results is that the heat supplied by cycling promoted increased maturation of zinc phosphate cements and glass ionomer, as well as increased the degree of monomer conversion in resin cement, resulting in an increased resistance at the bond interface ${ }^{9}$. The average bond strength of zinc oxide was the only one that showed significant reduction after thermal cycling, possibly due to the degradation of the structure of its molecules. Zinc oxide has water as a trapped by-product and therefore, its setting reaction accelerate in aqueous media. Moreover, the hydrolysis of its molecules results in a faster degradation when compared to other cements tested ${ }^{40}$. The evaluation of the four types of cements tested in this study confirmed the initial hypothesis that resin cements, because of their chemical and mechanical properties, behave better after thermocycling as compared to other cements. However, glass ionomer-based cements and zinc phosphate also performed better than the expectations and may thus be safely used for cementing.

\section{Conclusions}

Based on the results obtained in the present study, we conclude that the glass ionomer and resin cements were associated with average values of bond strength, significantly higher than the others did prior to thermal cycling. Thermocycling promoted an increase in the bond strength for all cements except the zinc oxide cement, for which a significant decrease in bond strength was observed. After thermal cycling, the resin cement was associated with the highest average value of bond strength, significantly higher than the other sealers.

\section{Referências}

1. Lekholm U, Gunne J, Henry P, Higuchi K, Lindén U, Bergström $C$, et al. Survival of the Brånemark implant in partially edentulous jaws: a 10-year prospective multicenter study. Int J Oral Maxillofac Implants 1999;14:639-645.

2. Scholander S. A retrospective evaluation of 259 single-tooth replacements by the use of Brånemark implants. Int J Prosthodont 1999;12:483-491.

3. Adell R, Lekholm U, Rockler B, Brånemark PI. A 15-year study of osseointegrated implants in the treatment of the edentulous jaw. Int J Oral Surg 1981;10:387-416.
4. Brånemark PI, Adell R, Breine U, Hansson BO, Lindström J, Ohlsson A. Intra-osseous anchorage of dental prosthese I. Experimental studies. Scand J Plast Reconstr Surg 1969;3:81-100.

5. Chee W, Jivraj S. Screw versus cemented implant supported restorations. Br Dent J 2006;20:501-507.

6. Hebel KS, Gajjar RC. Cement-retained versus screw-retained implant restorations: achieving optimal occlusion and esthetics in implant dentistry.J Prosthet Dent 19970;77:28-35.

7. Ramp MH, Dixon DL, Ramp LC, Breeding LC, Barber LL. Tensile bond strengths of provisional luting agents used with an implant system.J Prosthet Dent 1999;81:510-514.

8. Covey DA, Kent DK, Junior HASG, Koka S. Effects of abutment size and luting cement type on the uniaxial retention force of implant-supported crowns. J Prosthet Dent 2000; 83:344-48.

9. Akça K, Iplikçioğlu H, Cehreli MC. Comparison of uniaxial resistance forces of cements used with implant-supported crowns. Int J Oral Maxillofac Implants 2002;17:536-542.

10. Assif D, Marshak B, Horowitz A. Analysis of load transfer and stress distribution by an implant-supported fixed partial denture. J Prosthet Dent 1996;75:285-591.

11. Rodrigues Filho $L E$, Burger $L A$, Kenshima $S$, Bauer JR, Medeiros IS, Muench A. Effect of light-activation methods and water storage on the bonding to densely sintered zirconiumoxide ceramic. Dental Materials 2009;25:172-173.

12. Toledano $M$, Osorio R, Osorio E, Aguilera FS, Yamauti M, Pashley $\mathrm{DH}$, et al. Durability of resin-dentin bonds: effects of direct/indirect exposure and storage media. Dent Mater 2007; 23:885-92

13. Breeding LC, Dixon DL, Bogacki MT, Tietge JD. Use of luting agents with an implant system: Part I. J Prosthet Dent 1992;68:737-741.

14. Ekfeldt A, Carlsson GE, Börjesson G. Clinical evaluation of single-tooth restorations supported by osseointegrated implants: a retrospective study. Int J Oral Maxillofac Implants 1994;9:179-183.

15. White SN, Yu Z, Tom JF, Sangsurasak S. In vivo marginal adaptation of cast crowns luted with different cements. J Prosthet Dent 1995;74:25-32.

16. Levine RA, Clem DS 3rd, Wilson TG Jr, Higginbottom F, Saunders SL. A multicenter retrospective analysis of the ITI implant system used for single-tooth replcements: preliminary results at 6 or more months of loading. Int J Oral Maxillofac Implants 1997;12:237-242.

17. Moberg LE, Köndell PA, Kullman L, Heimdahl A, Gynther GW. Evaluation of single-tooth restorations on ITI dental implants. A prospective study of 29 patients. Clin Oral Implants Res 1999;10:45-53.

18. Scacchi M. The development of the ITI Dental Implant System. Part 1: a review of the literature. Clin Oral Implants Res 2000;11:8-21. 
19. Scacchi M, Merz BR, Schär AR. The development of the ITI Dental Implant System. Part 2: 1998-2000: Steps into the next millennium. Clin Oral Implants Res 2000;11:22-32.

20. Squier RS, Agar JR, Duncan JP, Taylor TD. Retentiveness of dental cements used with metallic implant components. Int J Oral Maxillofac Implants 2001;16:793-798.

21. Khraisat A, Stegaroiu R, Nomura S, Miyakawa O. Fatigue resistance of two implant/abutment joint designs. J Prosthet Dent 2002;88:604-610.

22. Levine RA, Clem D, Beagle J, Ganeles J, Johnson P, Solnit $\mathrm{G}$, et al. Multicenter retrospective analysis of the solid-screw ITI implant for posterior single-tooth replacements., Int J Oral Maxillofac Implants 2002;17:550-556.

23. Mansour A, Ercoli C, Graser G, Tallents R, Moss M. Comparative evaluation of casting retention using the ITI solid abutment with six cements. Clin Oral Implants Res 2002 ;13:343348.

24. Vigolo P, Givani A, Mayzoub Z, Condioli G. Cemented versus screw-retained implant-supported single-tooth crowns: a 4-year prospective clinical study. Int J Oral Maxillofac Implants 200;19:260-265.

25. Cortellini D, Valenti M, Canale A. The metal-free approach to restorative treatment planning. Eur J Esthet Dent 2006;1:230-247.

26. Pan YH, Ramp LC, Lin CK, Liu PR. Comparison of 7 luting protocols and their effect on the retention and marginal leakage of a cement-retained dental implant restoration. Int J Oral Maxillofac Implants 2006;21:587-592.

27. Emms M, Tredwin CJ, Setchell DJ, Moles DR. The effects of abutment wall height, platform size, and screw access channel filling method on resistance to dislodgement of cement-retained, implant-supported restorations. J Prosthodont 2007;16:39.

28. Zarone F, Sorrentino R, Traini T, Di lorio D, Caputi S. Fracture resistance of implant-supported screw- versus cement-retained porcelain fused to metal single crowns: SEM fractographic analysis. Dent Mater 2007;23:296-301.

29. Abbo B, Razzoog ME, Vivas J, Sierraalta M. Resistance to dislodgement of zirconia copings cemented onto titanium abutments of different heights. J Prosthet Dent $2008 ; 99: 25-29$.

30. Christensen GJ. Three-unit fixed prostheses versus implant-supported single crowns. J Am Dent Assoc 2008;139:191-194.

31. Dudley JE, Richards LC, Abbott JR. Retention of cast crown copings cemented to implant abutments. Aust Dent J 2008;53:332-339.

32. Mehl C, Harder S, Wolfart M, Kern M, Wolfart S. Retrievability of implant-retained crowns following cementation. Clin Oral Implants Res 2008;19:1304-1311.

33. Rappelli G, Corso M, Coccia E, Camaioni E, Di Felice R, Procaccini $M$. In vitro retentive strength of metal superstructures cemented to solid abutments. Minerva Stomatol 2008;57:95101.

34. Valenti M, Valenti A. Retrospective survival analysis of 261 lithium disilicate crowns in a private general practice. Quintessence Int 2009;40:573-579.

35. Wolfart S, Eschbach S, Scherrer S, Kern M. Clinical outcome of three-unit lithium-disilicate glass-ceramic fixed dental prostheses: up to 8 years results. Dent Mater 2009;25:63-71.

36. Fasbinder DJ. Clinical performance of chairside CAD/CAM restorations. J Am Dent Assoc 2010;137:22S-31S.

37. Marshall SJ, Bayne SC, Baier R, Tomsia AP, Marshall GW. A review of adhesion science., Dent Mater 2010;26:11-16.

38. Tarica DY, Alvarado VM, Truong ST. Survey of United States dental schools on cementation protocols for implant crown restorationse., J Prosthet Dent 2010;103:68-79.

39. Magne $P$, Magne $M$, Jovanic $S$. An esthetic solution for single implant restoration - Type III porcelain veneer bonded to a srew retain custom abutment: A clinical report. J Prosthet dent 2008; 99;2-7.

40. Anusavice KJ. In: Anusavice KJ, editor. Phillips' science of dental materials. 11th ed. St. Louis: Saunders Co; 2003. p. 481487.

Recebido em : 09/06/2017

Aprovado em: 21/06/2017

Os autores declaram que não há conflitos de interesse.

\section{Corresponding author:}

Laís Regiane da Silva-Concílio

Expedicionário Ernesto Pereira St, 110 - Centro - Taubaté SP, BRAZIL, 12020-330

PHONE: 00551236254149

FAX: 005512 3635-4968

E-mail: regiane1@yahoo.com 


\title{
Efeito do agente de cimentação sobre a resistência de ligação do disilicado de lítio baseado em cerâmica e do pilar de titânio submetido ao envelhecimento artificial
}

\begin{abstract}
Resumo
Objetivos: Este estudo teve como objetivo avaliar a resistência de união (RU) de uma interface de implante cerâmico coping-abutment de acordo com o agente de cimentação, antes e depois da ciclagem térmica (CT). Metodologia: Quarenta copings e pilares cerâmicos (PC) foram divididos em quatro grupos ( $n=10$ ): OZ (óxido de zinco eugenol livre), FZ (fosfato de zinco), IVM (ionômero de vidro modificado com resina) e CR (cimento de resina adesiva). O teste RU foi realizado usando uma máquina de teste universal antes e depois do CT. A análise de variância (ANOVA) e o teste de Tukey $(p<0,05)$ foram realizados. Resultados: Os resultados mostraram que, antes do $C T$, os valores variaram de 50,77 N (OZ) a 240,21 N (IVM). Após CT, os valores mostraram resultados intermediários - 3,5 N (OZ) e 330,66 $\mathrm{N}(\mathrm{CR}), 90,58 \mathrm{~N}$ (FZ) e 280,43 N (IVM). OZ realizou o pior, tanto antes quanto depois do CT. Antes do CT, o IVM tinha o valor mais alto. Após CT, CR teve o maior valor de RU. Conclusões: $O$ processo de envelhecimento influenciou e inverteu os resultados dos grupos IVM e CR e teve um impacto negativo maior no grupo OZ.
\end{abstract}

Keywords: Agente cimentante; Disilicato de lítio; Envelhecimento artificial. 